\title{
Application of 4G (LTE) Private Network Technology in Fire Emergency Communications
}

\author{
Zhang Lei ${ }^{1}$ and Yuan Mingming ${ }^{2}$ \\ Shenyang Fire Research Institute of Ministry of Public Security Shenyang 110035
}

Keywords: LTE; Emergency communications; OFDM; B-TrunC

\begin{abstract}
This article mainly elaborated the current status of emergency communications for firefighting forces, analyzed the current situation of the use of emergency communications equipment for firefighting forces, and also introduced the challenges faced by fire emergency communications in the new era. Finally, the technical advantages and networking structure of 4G (LTE) private network, and the current application of China's LTE private network were introduced.
\end{abstract}

\section{Introduction}

At present, with the rapid development of the social economy, the process of urbanization is accelerating, and a large number of high-rise underground buildings, super large-scale complex buildings and petrochemical enterprises have emerged, bringing tremendous pressure and challenges to firefighting and rescue work. In the actual firefighting and rescue operations of firefighting forces, there are also problems that emergency communication equipment construction does not meet the needs of the new situation and new tasks; the coverage of emergency communication networks is uneven; the existing signal coverage technology means cannot meet the actual firefighting needs, which seriously affects the actual results of emergency communication guarantees.

\section{Firefighting Forces Existing Wireless Communication Means}

At present, China's fire emergency communications equipment mainly includes satellite communications (portable stations, static communications, mobile communications, satellite phones, etc.), ultra-short wave communications (hand-held, relay), short-wave communications (short-wave devices) and public network communications (communication methods such as POC mobile phones and $3 / 4 \mathrm{G}$ image transmission equipment), and the main communication methods in disaster relief sites are based on narrow-band $350 \mathrm{M}$ stations. From the perspective of system construction, the construction of the communications network, such as the satellite from headquarters of disaster sites to headquarter command centers is relatively complete and the system is operating stably, which basically meets the needs of rescue. However, due to the adverse environmental impacts in rescue sites, it is difficult for the communication coverage network to achieve full coverage. There are many blind spots in communication, and basic voice communication is difficult to guarantee. Image communication is more difficult to meet the commanding demand of flat, especially in underground, high-rise and tunnel mountainous buildings. It is difficult to effectively guarantee the communication of voice and image data in disaster sites when the public network is broken.

\section{G private network application background and requirements}

\section{Status Quo of Rescue Emergency Communications in Urban Major Disasters.}

At the present stage, with the acceleration of urbanization in China, more and more people are flooding into cities. In order to achieve higher space utilization, high-rise, large-scale complexes and underground buildings in cities are increasingly dense. To meet people's traffic needs, subways, underground tunnels and other facilities are also increasing. These areas are characterized by large space, severe signal shielding, multiple obstructions, dense personnel and many blind spots, where disaster coverage does not exceed $5 \mathrm{~km}$. Once a disaster occurs, it will bring great difficulties to firefighting and rescue emergency communications. The requirements for firefighting emergency 
communications in these areas are: focusing on the coverage of signal coverage on-site plane, on high and underground.

\section{Status Quo of Emergency Rescue of Geological Disaster Accidents.}

At present, geological disasters have become more frequent in China. Earthquakes, mudslides and landslides have occurred from time to time. These disasters are characterized by large scope of disasters, damage to roads, interruptions in power and optical cables and paralysis of public networks, which brings great difficulties. The requirements of fire emergency communications in these areas are: to achieve signal coverage at disaster sites, and to solve the communication problems between command centers to front command centers and front command centers to search and rescue teams, and to consider the problems of lightening, miniaturization and power supply security of the equipment.

\section{The Characteristics of Emergency Communications Relying on Public Network.}

Fire emergency rescue has the characteristics of suddenness, complexity, uncertainty and urgency, which brings great difficulties to emergency communications. In fire rescue site, blind spots of public networks may be caused by the interruption of building power and the destruction of communications equipment. At the same time, the start of fire fighting facilities may also block public network transmission signals. On the other hand, disaster sites may have public networks, but we do not have the right to manage public networks. However, the capacity of base stations in public networks is limited. Other rescue forces and on-site people occupy resources, causing public networks congestion. Geological disasters may also cause damage to the public network base station transmission lines. Therefore, fire emergency communications cannot rely too much on public network communications and can only use public network communications as an auxiliary communication method.

\section{Comparison of 4G Technology with Other Wireless Technologies.}

Based on many limitations of traditional narrowband voice and public network communications, at present, fire emergency communications urgently need an exclusive, stable and quick deployable wireless private network signal coverage system that can realize disaster-free scenes without blind spots, which can be used in commanding the transmission of voice, image and data. From the perspective of the mature broadband wireless communication technologies currently used, the commonly used technologies include WIFI, MESH, microwave, and 4G-LTE technologies. The following are the comparisons of these wireless coverage technologies. :

\section{2.4G WIFI}

- High bandwidth and poor mobility, which is suitable for small-scale use in fixed sites;

- The actual transmission distance is generally less than 100 meter and the connection is very unstable after exceeding a certain distance;

2. 2.4G/5.8G Mesh

- Each wireless node can send and receive with good scalability;

- Multi-routing is non-core, difficult to manage, requires on-site configuration and is per-hop forwarding attenuation due to the limitation device composition;

3. Microwave

- Mostly used for one-way, one-to-one or one-to-many use, which is easily obstructed and causes signal attenuation and cannot form networks;

- The number of access terminals is limited and is susceptible to interference;

4. $4 \mathrm{G}$ private network

- Simple implementation, small delay, large coverage, and high-speed data transmission from point to multi-point can be achieved;

- TD-LTE in 4G signals is a domestic technology. It is a mature system widely used by operators. China's B-TrunC broadband trunking technology has become PPDR (Public Protection and Disaster Relief) broadband trunking air interface standard recommended by ITU-R (International Telecommunication Union Wireless Bureau). 
From the above comparison, it can be seen that $4 \mathrm{G}$ private network wireless coverage technology has great advantage in emergency rescue compared with other coverage technologies.

\section{G Technology Introduction}

This technology is the fourth generation mobile phone communication standard, referring to the fourth generation mobile communication technology, and the foreign language abbreviation is 4G. The technology includes both TD-LTE and FDD-LTE. (Strictly speaking, LTE is only 3.9G. Despite being promoted as a $4 \mathrm{G}$ wireless standard, it is not actually recognized by $3 \mathrm{GPP}$ as the nextgeneration wireless communication standard IMT-Advanced described by the International Telecommunication Union. Therefore, it has not yet reached the $4 \mathrm{G}$ standard in strict sense. Only the upgraded version of LTE Advanced can meet the requirements of International Telecommunications Union for $4 \mathrm{G}$.)

$4 \mathrm{G}$ integrates $3 \mathrm{G}$ and WLAN, enabling fast transmission of data, high quality, audio, video and images. $4 \mathrm{G}$ is capable of downloading at more than 100Mbps, which is 25 times faster than current home broadband ADSL (4M), and can meet almost any user's requirements for wireless services. In addition, 4G can be deployed in areas which are not covered by DSL and cable modems, and then extend to the entire area. Obviously, 4G has unparalleled superiority.

\section{Comparison of 4G Technology and Other Fire Emergency Communication Technologies}

Table 1. Comparison of 4G Technology and Other Fire Emergency Communication Technologies

\begin{tabular}{|c|c|c|c|c|c|}
\hline & $\begin{array}{c}\text { Analog Inter- } \\
\text { com }\end{array}$ & $\begin{array}{c}\text { Narrowband } \\
\text { analog clus- } \\
\text { ter }\end{array}$ & $\begin{array}{c}\text { Narrowband } \\
\text { digital cluster }\end{array}$ & $\begin{array}{c}\text { COFDM } \\
\text { Wireless im- } \\
\text { age transmis- } \\
\text { sion }\end{array}$ & $\begin{array}{c}\text { 4G-LTE Pri- } \\
\text { vate network }\end{array}$ \\
\hline Bandwidth & - & $36 \mathrm{Kbps}$ & $228 \mathrm{Kbps}$ & $20 \mathrm{Mbps}$ & $\begin{array}{c}\text { DL:100Mbps } \\
\text { UL:50Mbps }\end{array}$ \\
\hline Delay & $20 \mathrm{~ms}$ & $200 \mathrm{~ms}$ & $500 \mathrm{~ms}$ & $250 \mathrm{~ms}$ & $5 \mathrm{~ms}$ \\
\hline $\begin{array}{c}\text { Transmission } \\
\text { Distance }\end{array}$ & $1-5 \mathrm{KM}$ & $5-10 \mathrm{KM}$ & $5-10 \mathrm{KM}$ & $10-50 \mathrm{KM}$ & $5-100 \mathrm{KM}$ \\
\hline $\begin{array}{c}\text { Anti- } \\
\text { interference } \\
\text { Ability }\end{array}$ & Poor & Poor & General & General & High \\
\hline Safety & Poor & Poor & Poor & General & High \\
\hline $\begin{array}{c}\text { Transmission } \\
\text { Method }\end{array}$ & $\begin{array}{c}\text { Point-to- } \\
\text { multipoint }\end{array}$ & $\begin{array}{c}\text { Point-to- } \\
\text { multipoint }\end{array}$ & $\begin{array}{c}\text { Point-to- } \\
\text { multipoint }\end{array}$ & Point-to-point & $\begin{array}{c}\text { Point-to- } \\
\text { multipoint }\end{array}$ \\
\hline $\begin{array}{c}\text { Spectrum Uti- } \\
\text { lization }\end{array}$ & Low & Low & Low & Low & High \\
\hline $\begin{array}{c}\text { Business Sup- } \\
\text { port }\end{array}$ & Voice & Voice & Voice & Voice, video & $\begin{array}{c}\text { Voice, video, } \\
\text { positioning }\end{array}$ \\
\hline
\end{tabular}

Compared with traditional narrow-band communication, 4G-LTE private network has greatly improved the transmission rate, delay, anti-jamming capability and multi-service support capabilities of the uplink and downlink. Large bandwidth and low delay can meet the actual needs of the transmission of video, voice, data, positioning and other services in firefighting. 


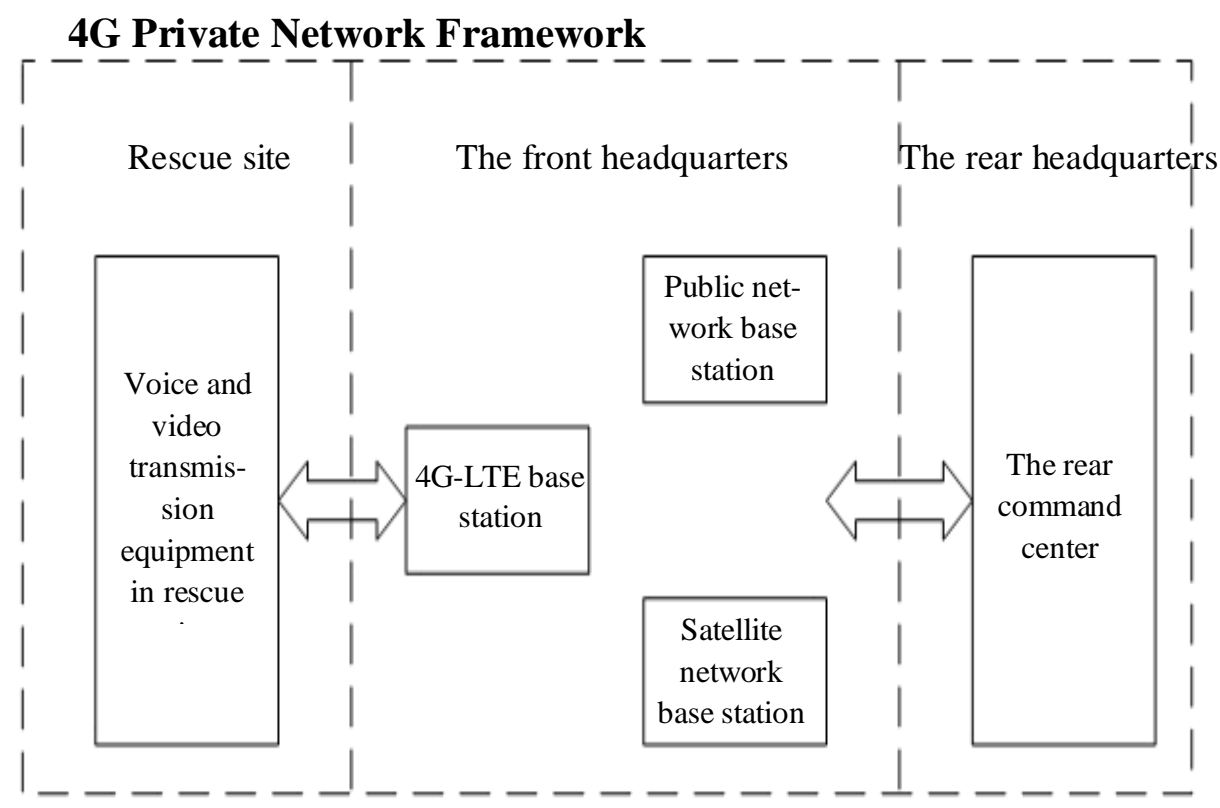

Fig. 1. 4G private network frame

In this framework, the 4G-LTE private network base station consists of an antenna, a feeder and a host. The $4 \mathrm{G}$ private network base station is placed in an open and high-geographic area. The base station antenna can be selected to be omnidirectional or directional type to ensure that the disaster site is free of blind spots. The base station can use TD-LTE technology of China's independent intellectual property rights. In order to enhance the diffraction capability of $4 \mathrm{G}$ wireless signals and reduce the loss of signals in space, the transmit frequency band of the equipment can be set to the low-frequency emergency frequency band, which can expand the coverage of the equipment and reduce the blind area. The equipment can integrate TD-LTE private network, Mesh, WIFI and other signals, and add the network management function. The communication equipment used in the disaster site can be connected to the front headquarters through 4G private network, Mesh, WIFI, etc. Under the premise of public network, the front headquarters can connect with the rear command center through the public network, and the front headquarters can connect with the rear command center through the satellite station and other networks in the absence of the public network.

\section{G-LTE Private Network Application}

The main standard of $4 \mathrm{G}$ private network is B-TrunC (Broadband Trunking Communication), which is a LTE-based "LTE digital transmission + cluster voice communication" private network broadband cluster system standard formulated by Broadband Cluster (B-TrunC) Industry Alliance. In November, 2012, the project was formally launched and started at China Communications Standards Association (CCSA), and in November, 2014, it became PPDR (Public Protection and Disaster Relief) broadband cluster air interface standard recommended by ITU-R (International Telecommunication Union Radio Bureau). At present, it has been applied in the private networks of some industries, such as government affairs networks, electricity, public security, petroleum, airports and coal mines.

The LTE-based broadband trunked communications (B-Trun C) system operates in $1.4 \mathrm{GHz}$ and $1.8 \mathrm{GHz}$ bands, as shown in the following table. The system can also be used in other frequency bands in compliance with the national radio management requirements.

Table 2. B-Trun $\mathrm{C}$ defining $4 \mathrm{G}$ private network band

\begin{tabular}{|c|c|c|}
\hline Working frequency (FUL_low - UL_high) & Channel bandwidth & Duplex mode \\
\hline $1447 \mathrm{MHz}-1467 \mathrm{MHz}$ & $10 \mathrm{MHz} 、 20 \mathrm{MHz}$ & TDD \\
\hline $1785 \mathrm{MHz}-1805 \mathrm{MHz}$ & $\begin{array}{c}1.4 \mathrm{MHz} 、 3 \mathrm{MHz} \\
5 \mathrm{MHz} 、 10 \mathrm{MHz}\end{array}$ & TDD \\
\hline
\end{tabular}

In September 2017, the Fire Bureau of the Ministry of Public Security issued Technical Plan for 
the Construction of Rescue Emergency Communication System for Urban Major Accidents and Geological Disasters (Trial). The $4 \mathrm{G}$ private network base station is defined in the plan, which is used to realize the coverage of the $4 \mathrm{G}$ private network signals of front headquarters and accident sites. The coverage radius shall be no less than $5 \mathrm{~km}$ in the open area of the field, no less than $2 \mathrm{~km}$ in the urban buildings and no less than $800 \mathrm{~m}$ in the signal shielding area. The $4 \mathrm{G}$ private network base station in firefighting is used for temporary erection. Currently, it is only used as the communication link between the accident site and the front headquarters and does not form a broadband private network cluster.

\section{Questions and Suggestions}

Currently, the $4 \mathrm{G}$ private network base station for fire protection is still in the initial construction trial phase. The equipment can only be used alone and only small coverage can be formed. Multiple devices cannot be cascaded. Since there is no dedicated frequency point for firefighting alone, it may interfere with other $4 \mathrm{G}$ private network systems.

It is suggested that the construction of fire emergency special network should strengthen the toplevel design, reasonable planning and overall consideration, build a unified and efficient emergency communication system that meets the actual needs of the current fire protection, and integrates the existing emergency communications equipment and network of fire protection to form a clear and concise connection and achieve the change of emergency communications from the "point" to "network" as soon as possible.

\section{Conclusion}

Due to its high bandwidth, low latency, large range and depth coverage, simple networking, rapid deployment, one-to-many transmission and mature applications, $4 \mathrm{G}$ private network technology can meet the needs of the new era of fire emergency communication and rescue commanding and contribute to the construction of firefighting information.

\section{References}

[1] Talking about the Application of Wireless Signal Coverage in Disaster Scene Based on 4G_LTE_Private Network. Cai Jianfeng. 2016.

[2] LTE Broadband Cluster Communication (B-TrunC) Technology White Paper. 2016.

[3] Fire Information Technology Application. Ministry of Public Security Fire Department. 2016.

[4] The Experience and Enlightenment of Foreign Emergency Response to Emergency Communication. Li Zheng. Xiao Wei. 2015 